Military Technical College

Cairo, Egypt $12^{\text {th }}$ International Conference on Applied Mechanics and Mechanical Engineering

(AMME

\title{
ACTIVE CONTROL EFFECT ON REDUCING NOISE AND RESONANCE AMPLITUDE OF CLAMPED-CLAMPED PLATE
}

\author{
Ghazy*M. R., and Elhady** A. M.
}

\begin{abstract}
Noise and vibration control of plates using active elements is presented here as a result of experimental work. The objective of this work is to study the possibility of controlling the noise and vibration of plates using a simple control regime. Active reduction of plate's noise and vibration is evaluated for a test steel plate excited using a B\&K exciter. Smart damping materials (piezo-ceramics) are used for accomplishing the process of reducing the plate vibration and born noise. The system is built up with an analogue to digital converter fed with the measured vibration signal after passing through a low-pass filter. The output is manipulated through a computer to produce an analogue signal using a digital to analogue converter, which is fed to the piezo-ceramic actuator without any frequency modifications. The actuator vibrates in response, to counter act and to damp the structure vibration. The test results show that the vibration peaks at multiple frequencies are reduced. It also shows that the structural borne noise is substantially reduced using smart damping materials, indicating the validity of its usage for industrial applications to reduce noise and vibration.
\end{abstract}

KEYWORDS: Active control, Smart materials, Piezo-ceramics, Vibration, Noise.

*Dep. of Mechanical Engineering Design, Faculty of Engineering, Zagazig University. **Dep. of Space Science, National Authority of Remote Sensing and Space Science, Egypt. 


\section{INTRODUCTION}

Piezo-ceramics can be used as both actuators and sensors, named piezo-actuators and piezo-sensors, due to its respective attributes of inverse piezoelectric effect and direct piezoelectric effect. One of the application fields of the piezoceramics is active vibration and noise control. Active vibration control is widely used because of its broad frequency response range, low additional mass, high adaptability and good efficiency. Comparing to the passive vibration control, closed loop active vibration control needs sensors to sense the vibration of the structure and actuators to suppress the vibration. Noise and vibration reduction and control of structure members using smart materials such as piezo-ceramics as sensors and actuators have been devoted a considerable attention recently.

Crawley and De Luis [3] are among the first who proposed piezo-ceramic material to be built in laminated beams to reduce its vibration. Agnes [1], developed a model for active suppression of vibration using piezo-electric actuators. Concepts and applications of using various techniques of electric circuits can be found in Carson [2]. Edberg, et-al [4], discussed the conversion of energy in piezoelectric materials and its role in enhancing passive damping.

Fanson and Caughey [5] carried out feed back using segmented piezo- ceramics, to control the vibration of elastic linkage mechanisms. They also gave an expression for the exciting moment on a beam caused by the piezo- ceramic actuator.

Ghoneim [6] used piezoelectric material to surface damping. Hagood, N. W., et al [7] and [8], tried modeling the dynamics of piezoelectric actuators when used for active control vibration of structure elements.

Many Industries, such as automotive and aerospace industries, have given this area a high attention. The use of piezoelectric elements for passive electronic damping has already been proven to work effectively in some commercial products. Several research works on absorption methods to reduce structural vibration have been reported. Hollkamp, J. and Gorden, R.W.,[9], showed that the piezoelectric absorber provides more vibration suppression compared to other types of damping techniques. Lesieutre, G.A., [11], is among the so many researchers who used piezoelectric materials to damp vibration of structures. Sung and Chen [12] used piezo-ceramics to control the vibration of flexible linkage mechanism.

Sun, D. and Tong, L., [13], modeled the interaction between the piezoelectric sensor and the considered structure; they took into consideration the effect of the adhesive layer between the sensor and the structure.

The objective of this study is to model the system and to explore the benefits of using smart damping materials (piezo-ceramics materials) in augmenting the performance of passive damping materials that are commonly used in a variety of applications. A test rig is constructed for measuring and comparing vibrations and structure-borne noise, and a series of experiments are conducted on a test plate. A brief description of the test rig is presented and an analysis of the averaged results obtained from testing the plate is discussed. 


\section{PROBLEM DEFINITION AND EXPERIMENTAL SET-UP}

It is required to establish the beneficiary of using the piezo-ceramic actuator for reducing the vibration levels and, consequently, the emitted noise of a steel plate. A homogenous, isotropic square steel plate of thickness $1[\mathrm{~mm}]$ is considered as a test specimen. The plate is fixed to a rigid steel frame, which is excited by a B\&K (4801) exciter of characteristics shown in Fig.1.

The equation of free vibration of the plate is [10];

$$
\frac{\partial^{4} w(x, y, t)}{\partial x^{4}}+2 \frac{\partial^{4} w(x, y, t)}{\partial x^{2} \partial y^{2}}+\frac{\partial^{4} w(x, y, t)}{\partial y^{4}}=C \frac{\partial^{2} w(x, y, t)}{\partial t^{2}}
$$

where

$w(x, y, t)$ is the deformation in the z-axis

After Fanson and Caughy [5], one can express the equation of forced vibration of the plate excited by the piezo-ceramic as:

$$
\frac{\partial^{4} w(x, y, t)}{\partial x^{4}}+2 \frac{\partial^{4} w(x, y, t)}{\partial x^{2} \partial y^{2}}+\frac{\partial^{4} w(x, y, t)}{\partial y^{4}}+C \frac{\partial^{2} w(x, y, t)}{\partial t^{2}}=q(x, y, t)
$$

where:

$w(x, y, t) \quad$ displacement at any point " $x, y$ " in direction " $z$ " at time "t";

$\mathrm{q}(\mathrm{x}, \mathrm{y}, \mathrm{t}) \quad$ actuating force per unit area of the plate, produced by the piezo-ceramic $C=\frac{12 \rho\left(1-v^{2}\right)}{E h^{3}}$

$E, \rho, v, h \quad$ are elastic modulus, density, Poison's ratio and thickness of the plate.

The following boundary conditions apply along all clamped edges of the plate:

$w=0$;

$\theta_{x}=0 ;$ and

$\theta y=0$.

With the appropriate initial values be taken into considerations.

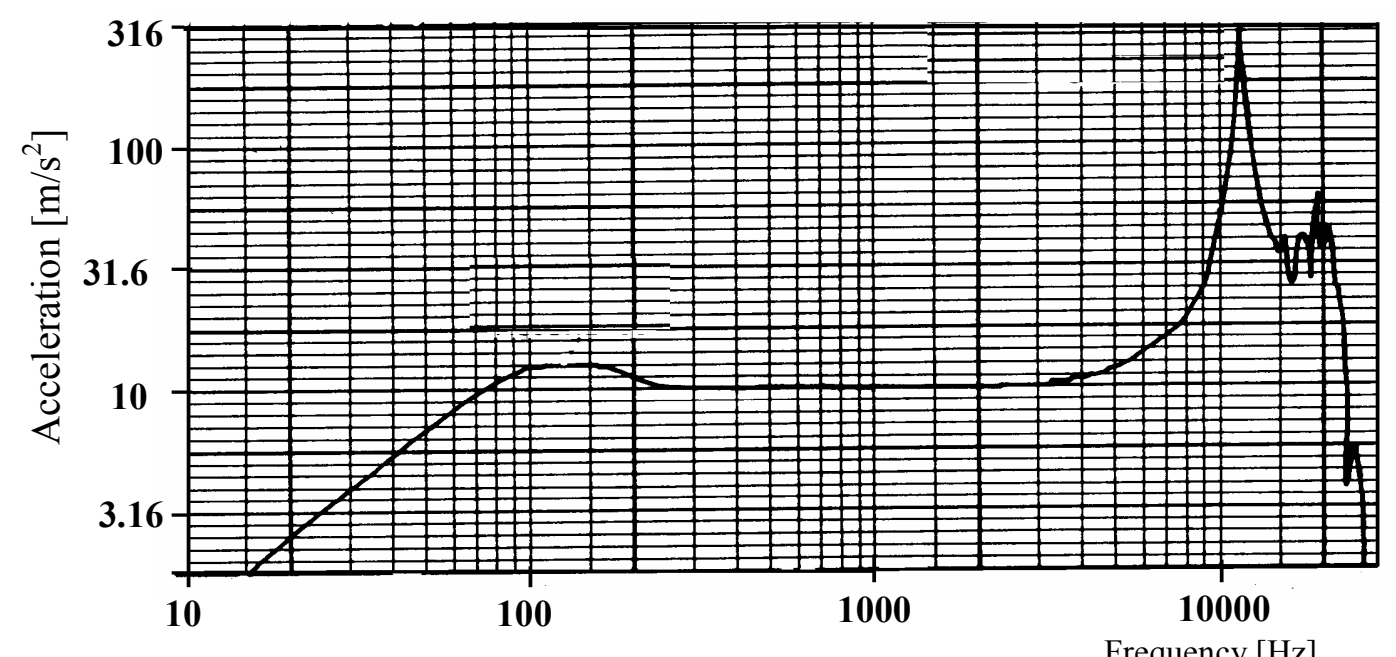

Fig.1. Characteristics of the used B\&K 4801 exciter. 
A test stand, shown in Fig.2. was constructed for testing and evaluating the effectiveness of using piezoelectric materials for reducing structure-borne noise and vibration. The tests stand enables vibration and acoustic measurements conducted on a steel plate with clamped-clamped boundary conditions. The plate is clamped rigidly around its edges and excited over a broad band, ranging from $50-500 \mathrm{~Hz}$ The test stand was used to evaluate the effects of using piezoelectric materials on reducing the plate noise and vibrations.

The test stand constitutes an excitation frame, an electromechanical exciter (B\&K (4801)). The stand was then fixed to the walls of an anechoic chamber, for enabling performing noise measurements and preventing interference of noise from the shaking part.

The anechoic chamber walls compose sound insulation materials, to meet the test specifications, and are lined with acoustic foam.

Sound measurements were conducted with a microphone that hangs $1[\mathrm{~m}]$ from the plate center, in order to assess the sound generated by the plate vibrations.

The excitation frame is properly fixed to the supporting frame such that on one end it is connected to the electromechanical exciter and at the other end it supports the test plate. The frame is designed such that it does not have any flexible structural modes in the frequency range of testing. The frame also has a minimal surface profile in the horizontal direction, so that it does not pump too much air to the test plate when excited by the exciter. It was designed with relatively heavv-steel rods.



Fig.2. Schematic of the constructed test rig

The exciter connects to a small stiff plate near the apex of the pyramidal shape, and the test plate connects to a clamping frame at the base of the pyramid.

Series of tests to establish the validity of the test setup, prior to performing the experiments with the piezoelectric materials. These tests were aimed at choosing proper testing parameters. They were further intended to establish the excitation frame flexible modes to ensure they fall outside of the test range and do not affect the test data repeatability and linearity. These tests indicated the validity of the test setup for the experiments intended to be performed. 
The test plate used for this study is a galvanized steel plate $(400 \times 400 \times 1[\mathrm{~mm}])$. This test plate configuration was selected because it is commonly accepted in the automotive industry as the "standard" plate for evaluating noise and vibration effectiveness of various damping materials in the laboratory. The test plate was clamped into place with 12 bolts.

Two piezoelectric plates; a sensor and an actuator; $(72.5 \times 72.5 \times 0.127[\mathrm{~mm}])$ were glued to the test plate at its center, at both sides.

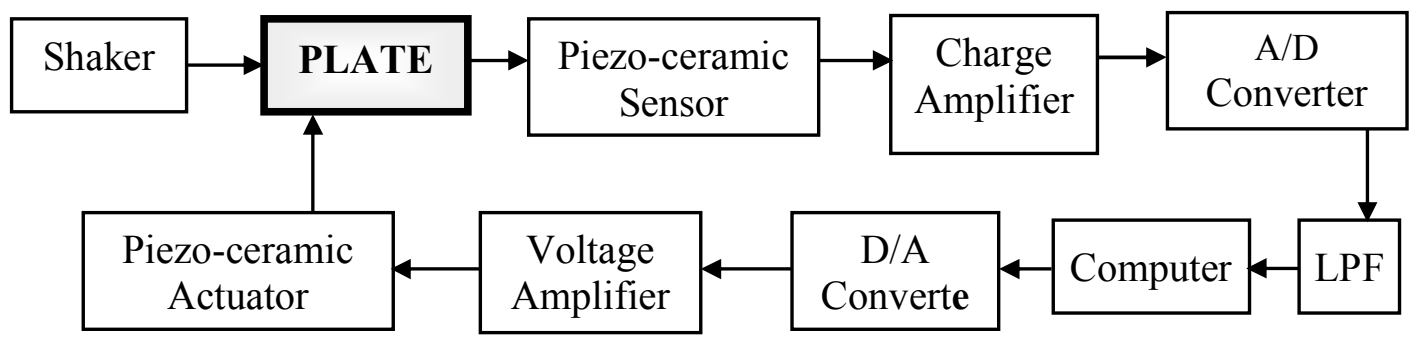

Fig.3. Schematic of the used Instrumentation

A schematic of the instrumentation used in the investigations is shown in Fig.3. The vibration signal is measured by a sensor is transformed into voltage by a charge amplifier, and then fed to a low pass filter. Then, the analogue voltage signal is converted into a digital signal fed to the computer through an analogue to digital converter. The computer outputs the actuating signal in an analogue form through a digital to analogue converter. The actuating signal is then magnified to 320 [volts] through a voltage amplifier.

\section{RESULTS AND DISCUSSION}

It is first worth to mention that, the presented vibrational acceleration of the tested plate are normalized by the frame vibrational acceleration, to account for any changes of the frame acceleration, that may occur from one test to another. Also, the figures show the mean of several repeated measurements carried out.

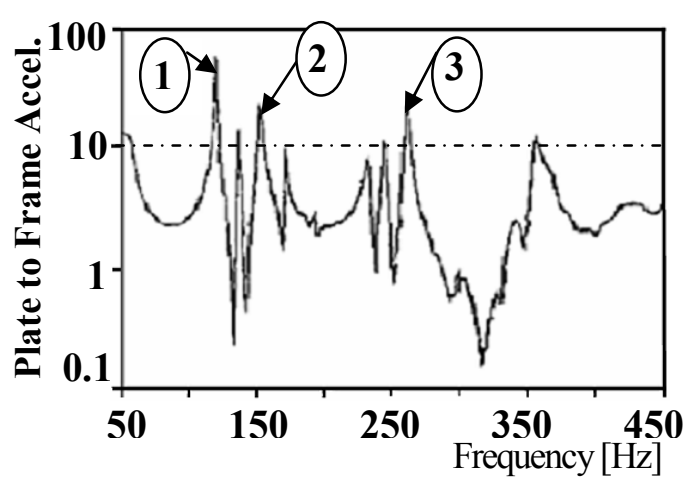

Fig.4-a. Measured vibration signal of the plate without actuating the piezo-ceramic

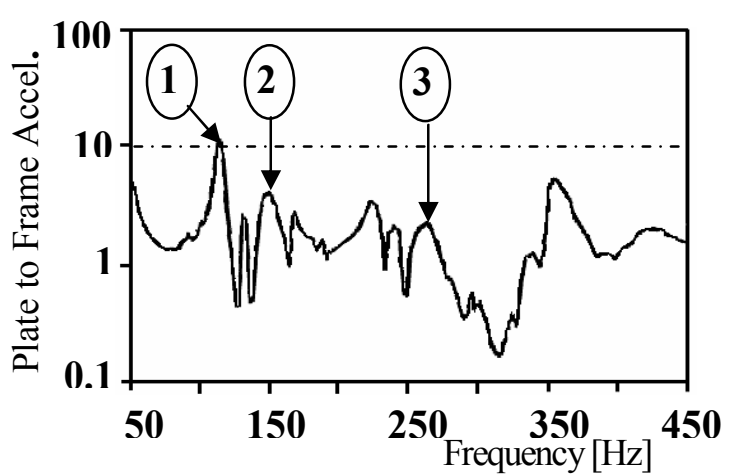

Fig.4-b Measured vibration signal of the plate when actuating the piezo-ceramic 




Fig.5-a. Measured noise signal without actuating the piezo-ceramic

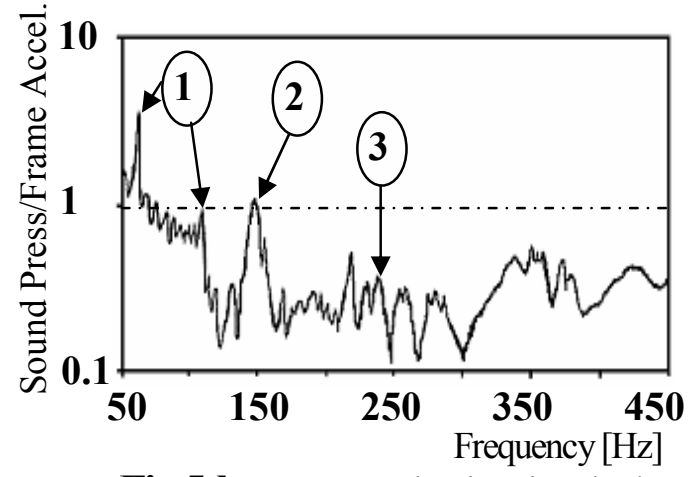

Fig.5-b. Measured noise signal when actuating the piezo-ceramic

It can be seen from the analysis of the measured vibration signals of the vibrating plate shown in Fig.4-a (without activating the piezo-ceramics), that the signal contains mainly components of the natural frequencies of the plate different modes of vibration. On activating the piezo-ceramics, the vibration signal measured is shown in Fig.4-b. The peaks of vibrational acceleration occurred mainly at 114, 138, 148, 170, 230, 245, 260 and $355[\mathrm{~Hz}$. The most significant peaks are marked by arrows and given numbers 1, 2 and 3. Same set of measurements of the noise signals are shown in Figs. 5-a (without activating the piezo-ceramics) and $5-b$ (when activating the piezo-ceramics).

Figures 4-b and 5-b do show clearly the enormous reduction in amplitudes at the nominated peaks when activating the piezo-ceramics.

\section{CONCLUSIONS}

A simple active vibration and noise control system fed the measured low vibration frequency without any modification to a piezo-ceramic damping element shows high efficiency in born noisy reduction and vibration response suppression. The application of active damping using piezo-ceramics for reducing noise and vibration in structures was examined by attaching piezo-ceramic pieces to a steel plate. The results show a significant reduction in the structural vibration, and the associated structure-borne noise, without adding any significant amount of weight to the structure. The experiments conducted in this study show that for many structures piezo-ceramic can provide a practical means for augmenting the vibration reduction effects of viscoelastic damping materials in lower frequencies. 


\section{REFERENCES}

[1] Agnes, G. S., 1995, "Development of a Model for Simultaneous Active and Passive Piezoelectric Vibration Suppression, "Journal of Intelligent Materials Systems Structure, 6, pp. 482-487.

[2] Carson, A. B., 1990, "Electrical Engineering: Concepts and Applications", AddisonWesley Publishing Co, New York, pp. 172-175.

[3] Crawley, E.F. and De Luis, J., 1987 " Use of Piezoelectric Actuators as Elements of Structures" AIAA Journal, Vol.25, pp 717-724.

[4] Edberg, D. L., Bicos A. S., and Fechter, J. S., 1991, "On Piezoelectric Energy Conversion for Electronic Passive Damping Enhancement, "Proceedings of Damping, San Diego, CA.

[5] Fanson, J.L., and Caughey, T.K., 1990, "Positive Position Feedback Control for Large Space Structures", AIAA Journal, Vol.28, No.4.

[6] Ghoneim, H., 1993, "Electromechanical Surface Damping Using Constrained Layer and Shunted Piezoelectric", SPIE Proceedings: Mathematics in Smart Structures, 1919, pp. 78-89.

[7] Hagood, N. W., Chung, W. H., and von Flotow, A., 1990, "Modeling of Piezoelectric Actuator Dynamics for Active Structural Control", J. Intell. Mater. Syst. Struct., 1, pp. 327-354.

[8] Hagood, N. W., and vou Flotow, A., 1991, "Damping of Structural Vibrations with Piezoelectric Materials and Passive Electrical Networks", Journal of Sound and Vibration, 146, No. 2, pp. 243-268.

[9] Hollkamp, J. and Gorden, R.W., "An Experimental Comparison of Piezo-electric and Constrained Layer Damping", Smart Mater. Struct. 4, August 1996.

[10] Inman, D. J., 1994, "Engineering Vibration", PRENTICE HALL, Englewood Cliffs, New Jersy 07632.

[11] Lesieutre, George A., "Vibration Damping and Control Using Shunted Piezoelectric Materials", The Shock and Vibration Digest, Vol. 30, No. 3, May 1998, pp.187-195

[12] Sung, C.K., and Chen, Y.C., 1991, "Vibration Control of the Elastodynamic Response of High Speed Flexible Linkage Mechanisms", ASME Journal of Vibration and Acoustics, Vol. 113, pp 14-21.

[13] Sun, D., and Tong, L., 2002, "Modeling and Vibration Control of Beams with Partially Debonded Active Constrained Layer Damping Patch", Journal of Sound and Vibration (2002), 252(3), 493-507. 